\title{
Research on the Relevancy of Employees' Self-Concept and
}

\section{Occupational Happiness}

— Take One Enterprise of Shandong's Province For Example

\author{
Qu Guoli ${ }^{1}$, Liu Lihui ${ }^{2}$, Sang Rui ${ }^{3}$ \\ 1.Economics and Management College, Northeast Dianli University, Jilin, Jilin 132012, China \\ 2.Management College, University of Science and Technology of China, Anhui, Heifei, 230026, \\ China \\ 3.Life Science College, Jilin University, Jilin, Changchun, 130012, China
}

Keyword: occupational environment, self-concept of occupation, occupational happiness.

Abstract. The employees' self-concept and occupational happiness could promote the development of enterprise at a certain degree. Then what kind of relationship do both of them exist. We try to study the relationship which exists in self-concept and occupational happiness in this paper, on the one hand it enriches the study results for the self-conception and occupational happiness, on the another hand, it provides one reference for the enterprise manager to formulate the effective policy.

\section{Introduction}

Self-concept refers to that people have stable opinion about themselves, namely self-knowledge. In other words, it is an experience of people for their existence. It involves that one person deepens his own understanding gradually by experience, introspection and others's feedback. Self-concept is an organic cognition institution, which consists of attitude, emotion, faith and values and so on, and throughout all of experiences and movements it organizes various specific habits, abilities, thoughts, opinions presented by the individual. In short, self-concept is a judgment and assessment of awareness in every aspect that the individuals for themselves or related to themselves. However, as significant content in career planning and guide, the occupational self-concept has an important influence on the personal career orientation. It is a part of entire personal self-concept, and it is also a mirror in which one person's entire self-concept reflects in career choosing and career development. It is easier to get the employees' acceptance and advance their enthusiasm indirectly if the enterprise takes learning the employee self and complete employee self as the work starting point.

Occupational happiness, is the lasting happiness sense, which is based on a certain requests needed to be satisfied. The potential ability is given the play, and the strength is increased during the main body engaged in one occupation. Employees' happiness, the happiness related to the job, and the occupational happiness and so on can be called by the joint name of job happiness. Domestic scholar thinks that the job happiness refers to the employees' positive emotions and awareness assessment in the work, and it can be mirrored by the satisfaction degree, the intention of dismission, and the negative and positive emotion. Occupational happiness is a footstone for the development of enterprise. Correspondingly, the employees can not have the rising enthusiasm for 
the work if they have no happiness. It also promotes the employees' work efficiency and boosts the progress of enterprise.

Now that the employees' self-concept and occupational happiness can boost the development of enterprise at certain degree. So what kind of relationship does exist in both of them.

\section{The Investigation on the Present Status of Employees' Self-Concept and Occupational Happiness}

Data and Sample. In this investigation, all of questionnaires issued are 50 portions. 41 portions has been recalled, and 30 portions are effective. There are 15 female persons. And there are 15 male persons. For the part of employees' self-concept in this questionnaire, the Question 29 is the psychological self-survey, and the Question 22, 23, 24 are the social self-survey, and the Question 26 is family self-survey. The Question 20, 21, 27 are job self-survey, and the Question 25 is moral self-survey, and the Question 28 is physiological self-concept. For the part of occupational happiness in this questionnaire, the Question 13 is survey of employees’ physical and psychological health, the Question 8 and Question 12 are the survey of value/ability embodying. The Question 14, 15 are social support survey, and the Question 6, 9 are income survey. The Question 7, 10, 11 are the working environment survey. According to the options order ABCDE , the scores are five, four, three, two and one in turns.

The Introduction of Enterprise Employees' Occupational Self-Concept. We can find through statistical analysis of this investigation that four kinds of questions exist in the occupational self-concept of this enterprise's employee. For the first aspect, it lacks the awareness of enterprise employees' occupational self-concept, and they do not have a reasonable orientation, and do not have a clear planning for self-development. Thus, they lack the sufficient understanding of career planning. Self-concept is weak and self-cognition ability is low, and the expectation they set up for themselves is too high and their ability can not satify this expectation, so they can not finish the work without a hitch, and the work enthusiasm will be declined dramatically by the negative emotion. For the second aspect, it is the understanding ability about that the employees' occupational self-concept is not sufficient. It mainly can not be defined accurately as the self-orientation. The self-evaluation is objective in some degree. Therefore, it can not be objective to analyze the condition of job, their professional skills and knowledge structure. It results in the incompletion of self-cognition. They can not choose the job according to their own advantages so that it causes that the current job is not the job they like and showing their talents in work becomes very difficult. For the third aspect, the employees' occupational targets are only to earn more money. The main problem of them is that they mainly pay much attention on the salary and social status, and the employees ignore other questions involved themselves. For the forth aspect, the expectation of employee set up for job is too high as well as their orientation, and the incompletion of self-cognition, the aima they set up conflict with their abilities at a certain degree. In meanwhile, they have no unclear career development and target, the employees lack the planning and definition for their careers.

The Introduction of the Employees' Occupational Happiness. This investigation suggests that the employees' occupational happiness has four kinds of features. The first feature is that the employee's education degree will become higher, and the employees' occupational happiness will become lower. The second one is that the index of female work happiness is higher than the index of male work happiness. The third one is that the difference of employees' work happiness is apparent in varied grades of employees. Among them, the top spot is that the employees' work happiness engage in 'managing' the post, and the second is that the employees engage in 
'technology' post, but the lowest is that the employees engage in 'business' post. And the fourth is that the index of work happiness of employees who have different working ages presents the condition of 'both ends are high, the middle is low'. In other words, the work happiness of the employees who are freshmen and have a long working age is higher than the employees who have a certain working age but it is not long comparatively.

\section{The Analysis of the Relationship between Employees' Self-Concept and Occupational Happiness}

Assumption of Study. Yang Feihuo's study suggests that subjective happiness of primary school teachers who have different self-concept level are different obviously, and the self-concept level has apparent positive correlation with the subjective happiness. Geng Xiaowei's college students study suggests that the exterior self-concept predicts the exterior happiness, and the interior self-concept predicts the interior happiness. Yang Shaoning and Kong Xianjun's studies suggest that the subjective happiness of college students whose self-concept is in different groups is different very apparently. Lingyu and others's studies suggest that the subjective happiness of college students whose self-concept is in different levels has different statistical significance, and the more active the self-concept will be, the higher the subjective happiness will be. Li Xicai's study on the students from the local normal schools suggests that the self-concept has very apparent correlation with the subjective happiness, that is to say, the higher the self-concept of college students will be, the higher subjective happiness will be. And it has the predictive foundation for the subjective happiness. Heying's study verifies that the happiness of the people with self-harmony is higher than the people with self-discrepancy.

Therefore, we assume in this paper that the employees' self-concept has a relation of positive correlation with their occupational happiness, in other words, the higher the employees' self concept will be, the higher their occupational happiness will be.

Data Analysis. As shown in diagram below, we take the scatter diagram analysis for each parts of scare after recycling the questionnaire. We get the relevancy regression equation of employee's self-concept and occupational happiness, $\mathrm{y}=-0.9261 \mathrm{x}+64.408$, and the value of $\mathrm{R} 2$ is $0.8137>80 \%$. It is approach to 1 , and it indicates that the reliability of data is higher. And the employee's self-concept has a relation of negative correlation with the occupational happiness. By further analyzing the data, we find that in the below.

Table 1 The regression analysis

\begin{tabular}{c|c}
\hline \multicolumn{2}{c}{ Regression statistics } \\
\hline Multiple R & 0.90206 \\
R Square & 0.813712 \\
Adjusted R Square & 0.806813 \\
Criterion error & 2.571131 \\
Observed value & 29 \\
\hline
\end{tabular}


Table 2 The variance analysis

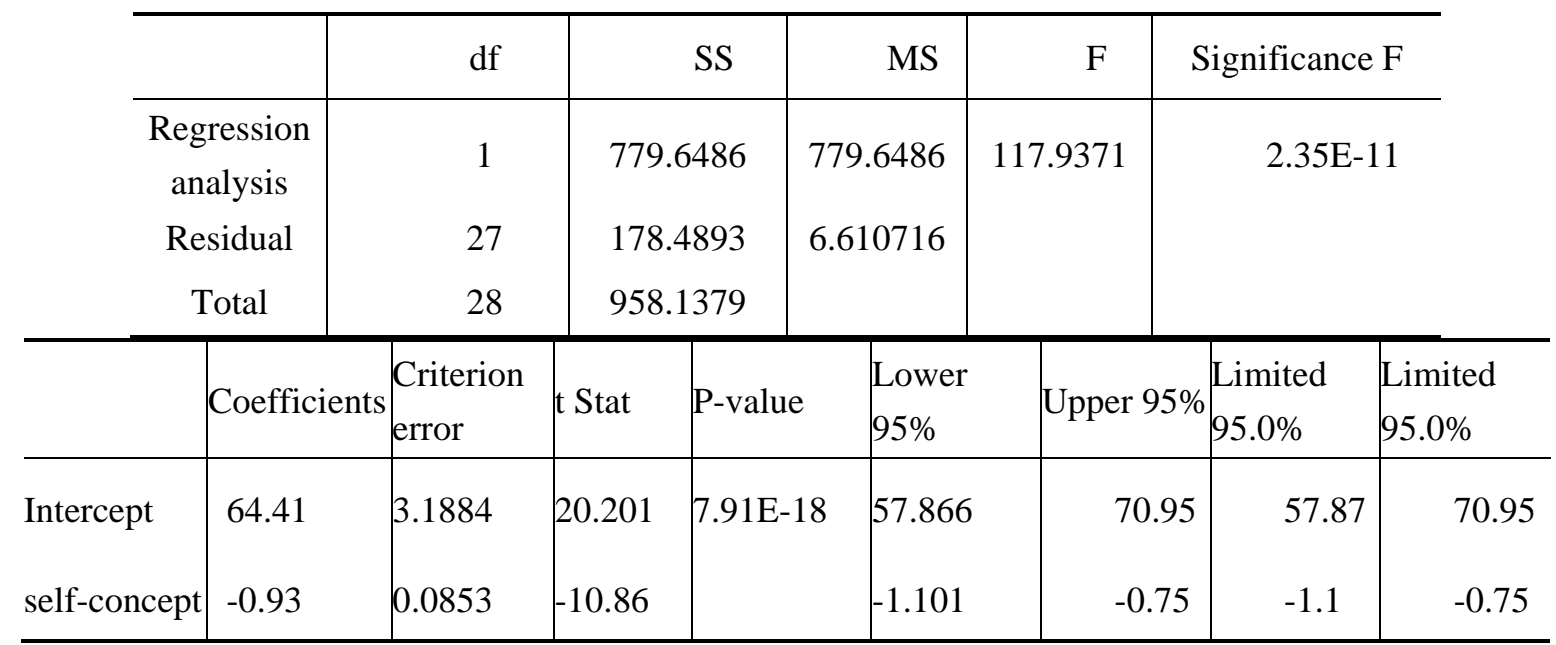

We can learn from table $4-3$ that the value of $\mathrm{P}$ is $7.9 \mathrm{E}-18<0.01$. We refuse the original assumption. And we support that the employees' self-concept has negative correlation relationship with their occupational happiness.

The Research Result. We can learn from the output result of table 4-3 that the coefficient of determination is $\mathrm{R} 2=0.813712$. The statistics of $\mathrm{t}$ with the estimated slope coefficient $\mathrm{b}^{\wedge}$ is -10.86 . It is greater obviously than 2.048. It is the critical value of statistics of $t$, and the value of $\mathrm{P}$ is 2.35E-11. And it is less than 0.05 obviously. All of the above suggest that the linear relation between self-concept and occupational happiness is obviously relative. In addition, we can learn from table 4-3 that the actual observed value of self-concept and occupational happiness is consistent with the model value comparatively. Thus, refusing original assumption of this enterprise employee's self-concept has the positive correlation relation with their occupational happiness. It confirms that employees' self-concept of China Unicorn in Liaocheng city has the negative correlation relation with the occupational happiness. In other words, the higher self-concept will be, the lower occupational happiness will be.

Restriction of This Research. Investigation samples are too few. The representativeness of samples needs to be improved further. The result of investigation has the boundedness at a certain degree, because the investigation object is state-owned enterprise. Correspondingly, the result only has the persuasion for state-owned enterprise relatively, and it can not represent employees' self-concept of in other industries. And it also has the negative correlation relation with their occupational happiness. Therefore, we could survey enterprises in various kinds of industry afterwards. The way of investigation is simple, and it just uses the questionnaire method. For increasing the persuasive degree of investigation result, on the foundation of questionnaire way in later investigation we can adopt the way of interview or observation for a certain part of employees.

\section{The Suggestions and Policies for Enterprise's Coping With the Relation of Employee's Self-Concept and Occupational Happiness}

Guide the Employees to Hold the Balance between Family and Work. As the work's rhythm has been speeded up day by day, the work pressures has become more serious every day. The employees will be tired in body and mind with facing the dual pressures from family and job, and their happiness will decline correspondingly. Therefore, the enterprise should emphasize on that adjusting the balance between family and work. Enterprise should promote the emphasis degree on 
the employees who have domestic difficulty and provide them with timely help. Enterprise should provide timely proper mediation for the employees who have significant democratic contradiction and improve their communication ability with their family. Enterprise should help the employees to establish the win-win concept and the harmony concept between work and family.

Provide Training and Help Employees' Development. Enterprise should provide the employees with more comprehensive training, and train the employees at regular intervals. Enterprise should provide the employees with team psychological coach about self-knowledge or psychological training, help the employees to understand and learn themselves rightly, and shape good movement about self-knowledge. Enterprise should establish the proper employees cultivation system, help the employees to learn their own ability rightly and formulate a career planning which adapts for themselves. Enterprise should provide the employees with the training of knowledge skill, professional skill which can help the employees, especially aiming the freshmen. Enterprise should help the employees to seek clear career development route, communicate more with the employees about their career planning to let the employees have more clear goal.

Pay More Attention to the Employees. Enterprise should strengthen the learning and understanding of employees' self-concept. For the enterprise, it should learn every employees' self-concept as much as possible. Every employee has strong self-concept although the request of entering state-owned enterprise is high relatively. However, it must be better to satisfy the employees and managers, and increase the employees' occupational happiness if learning the employees' self-knowledge, learning what the employees want to get, and what their demands are.

Adjust the Matching of the Employees and the Posts. The more we can learn the employees' self-concept, the more we can learn what the employees' favors and their aims in work are. And the enterprise can make proper adjustment according to their ideal jobs. For example, if the favor of a technical staff is to communicate with people, his ideal job will be selling. And the technology is not the work he shows his most interest in although it is his specialty. Although in state-owned enterprise, adjusting an employee to other post casually is difficult. But the enterprise can make proper adjustment within a certain scope. The happiness of this technical staff must be improved if let this technical staff does some work in publicity or selling when he is available. In this way these can safisfy the demand of ideal job.

Conduct the Employees to Make Clarification and Adjustment in Self-Concept. For the employees, the most dissatisfied for them is hidebound provisions of state-owned enterprise. The request of what entering state-owned enterprise is high relatively, because the stable salary and better condition are provided by the state-owned enterprise. The employees' self-concept has been strengthened generally, and it caused that the employees feel dissatisfied to every aspect of enterprise. For example, various approvals and signings, various complicated procedures, various range restriction, all of the things above can show their occupational happiness at a large degree. It can be better for employees that the employees can choose so- called ' take it as it comes'. The employees also adapt themselves to the provisions of enterprise, and adjust their own mindset. However, although they have experienced strict selection, and have worked in this enterprise, Enterprise should help the employees to clarify their responsibility in work, and to adjust self-concept. In this way, the employees’ occupational happiness will be improved.

\section{Acknowledgment}

This article is supported by general projects of the national natural science funds 'Based on the Occupational Self-conception the Promotion Mechanism of College Students’ Employment Quality: One Trace and Experiment Research'(71373251), and the doctor support project of social science 
funds in Jilin province “The Gap Measure Research on the Demand and Supply of Re-employment Policy about Unemployed People in Jilin province (2015BS14).

\section{References}

[1] Guo Yongyu. Personality Psychology:The Research on Human Nature and Its Difference[J].Social Science Sress, 2007:351-379.

[2] Feng Zeyu. The Research on Occupational Self-Concept: Thesis of Prospective and Recalling [J] Contemporary Enterprise Education, 2011, 24:1-2

[3] Zan Qisheng, Le Guoan. The Model about Multi-Layer Structure of Self-Concept[J]. The Research on Psychology and Action, 2003, 01: 68 -72.

[4] Wen Qingxiong, Chen Yinling. Introduction, Theory Frame Construction and Future Prospective of Career Happiness Concept[J]. Foreign Cultures and Economics and Its Management,2014,12:57.

[5] Geng Xiaowei, Zhangfeng, Zheng Quanquan. The Prediction of Interior Respect and Exterior Respect for College Students' Subjective Happiness[J]. Psychological Development and Education. 2009,1: 97-102

[6] Li Xicai. The Research on Self-Concept, Respect and Subjective Happiness of College Students in Local Normal School[J]. Academic Journal of Welnan Teachers College, 2009, 24: 65-67.

[7] Lingyu, Zhu Cuiying, Liu Wenli. The Relation of College Student's Self-Happiness and Self-Concept[J]. Chinese Journal of Healthy Psychology, 2008,16:1351-1352.

[8] Fang Biji, Liu Caixia, Fangqing, Chenfeng. The Research on the Relation of Medical Student's Self-Concept and Anxiety[J]. China’s Ministry of Science and Technology, 2014,11:113-128.

[9] An Rongjin. The Summary about the Research on Self-Concept[J]. Academic Journal of Pingxiang Technical College, 2008, 05:42-45.

[10] Zhang Yandong, Wei Zhenbo. The New Analysis of College Students' Career Planning in the View of Self-Concept Theory[J]. Coal Higher Education, 2013, 03:98-101

[11]Zheng Xiaoling. Summary about the Research Literature in Occupational Happiness of Domestic Teacher[J]. Impact Knowledge and Education People, 2011, 6:69-71.

[12] Wang Yumei, Xiong Lijuan. Research Presemt Status of Self-Concept in Nurse Specialty[J]. Journal of Qilu Nursing, 2014,21:58-60.

[13] Lidan, Yu Jianhua, Wang Yange, Yinliang, Wang Fuxing, Xiamian. The Influence of Personal Traits and Its Treat Method of Armed Police Recruit on Subjective Happiness[J]. Manage Journal of the People’s Liberation Hospital, 2013, 10:101-103.

[14] Long Chunjiang. On the Establishment of Teachers' Occupational Happiness under the Revolution Background of Distribution System with Colleges and Universities's Income[J].Academic Journal of Hei Longjiang Province Management Cadre Institute of Politics and Low, 2012, 04:161-164.

[15] Liu Wenhua. How Large does the Difference between Phase of Study and Gender have? The Research on 655 Teachers' Occupational Happiness[J]. Elementary and Middle School Administration, 2011, 07:37-38. 
[16] Qi Yongqin, Deng Fanmao. The Research on Vocational College Students' Self-Concept and Their Discipline[J]. Academic Journal of Hubei University of Economics(Humanities and Social Sciences),2014,11:162-163.

[17] Fan Cuiying, Song Xiaojun, Liu Huashan. Tendency of Time Management in College StudentS and Subjective Happiness[J].Psychological Development and Education, 2012, 28(1):99-104.

[18] Hansetal. Associations between Quantitative and Qualitative Job Insecurity And Well-being a Test in BeigianbBanks [J].Studies of Mgt \& Org, 2010, 01.

[19] Thomas A. Wright. Much More than Meets the Eye: the Role of Psychological Well-Being in Job Performance, Employee Retention and Cardiovascular Health[J].Dynamics,2010,(3):13. 